\title{
EVALUASI POSTUR KERJA PENGRAJIN BATIK TULIS ALEYYA BATIK DI YOGYAKARTA
}

\author{
Lindawati $^{1}$, Mulyono ${ }^{2}$ \\ ${ }^{1}$ Program Studi S1 Kesehatan Masyarakat, Fakultas Kesehatan Masyarakat, Universitas Airlangga \\ ${ }^{2}$ Departemen Keselamatan dan Kesehatan Kerja, Fakultas Kesehatan Masyarakat, Universitas \\ Airlangga \\ lindha.hip10@gmail.com
}

\begin{abstract}
Batik is a work that consists of several repetitive movements. Batik craftsmen working with posture unnatural will cause discomfort and musculoskeletal disorders. This study was conducted to evaluate the working posture on batik artisans in Aleyya Batik Yogyakarta. This research was a descriptive study with cross sectional approach. The population in this study using a total population of 15 people batik artisans in Aleyya Batik, Yogyakarta. Collecting data on the working posture batik artisans who will be judged by the method Rapid Entire Body Assessment (REBA) then be evaluated subjective complaints by the method of Nordic Body Maps (NBM). The results showed that the batik craftsmen working posture based assessment using REBA method showed that the working posture right side of batik craftsmen belong to the medium category by $86,67 \%$ and the working posture left side belong to the medium category by $80,00 \%$ so that the necessary remedial action. Subjective complaints based assessment using NBM method belong to the moderate risk level of 40,00\%, which means that it may take any corrective action in the future. Based on the discussion can be concluded that the working posture of batik craftsmen included in the medium category. Batik Aleyya owners should designed the seat workers which adapted to the batik craftsmen anthropometric so the working posture can be an ergonomic and does not lead to a subjective complaint.
\end{abstract}

Keywords: evaluation of working posture, batik craftsmen

\begin{abstract}
ABSTRAK
Membatik merupakan pekerjaan yang terdiri dari beberapa gerakan repetitif. Postur kerja pengrajin batik tulis yang tidak alamiah akan menyebabkan ketidaknyamanan kerja dan keluhan muskuloskeletal. Penelitian ini dilakukan untuk mengevaluasi postur kerja pada pengrajin batik tulis di Aleyya Batik Yogyakarta. Penelitian ini menggunakan desain deskriptif dengan metode pendekatan cross sectional. Populasi dalam penelitian ini menggunakan total populasi berjumlah 15 orang pengrajin batik tulis di Aleyya Batik, Yogyakarta. Pengambilan data mengenai postur kerja pengrajin batik tulis yang akan dinilai dengan metode Rapid Entire Body Assessment (REBA) kemudian dilakukan penilaian keluhan subyektif dengan metode Nordic Body Maps (NBM). Hasil penelitian menunjukkan bahwa postur kerja pengrajin batik tulis berdasarkan penilaian dengan metode REBA diketahui bahwa postur kerja bagian kanan pengrajin batik tulis tergolong dalam kategori sedang sebesar $86,67 \%$ dan postur kerja bagian kiri termasuk dalam kategori sedang sebesar 80,00\% sehingga diperlukan tindakan perbaikan. Keluhan subyektif yang dialami oleh pengrajin batik tulis dinilai dengan metode NBM diketahui bahwa sebagian besar tergolong dalam tingkat risiko sedang sebesar $40,00 \%$ yang berarti bahwa mungkin diperlukan adanya tindakan perbaikan dikemudian hari. Berdasarkan pembahasan dapat disimpulkan bahwa postur kerja kerja pengrajin batik tulis ketika melakukan pekerjaan termasuk dalam kategori sedang. Pemilik Aleyya Batik sebaiknya melakukan perancangan tempat duduk yang disesuaikan dengan antropometri pengrajin batik tulis sehingga postur kerja dapat ergonomis dan tidak menimbulkan terjadinya keluhan subyektif. Kata Kunci: evaluasi postur kerja, pengrajin batik tulis
\end{abstract}




\section{PENDAHULUAN}

Menurut Manuaba (2000) dalam Tarwaka (2015), Postur kerja yang tidak alamiah merupakan postur kerja yang menyebabkan posisi bagian-bagian tubuh bergerak menjauhi posisi tidak alamiah, misalnya pergerakan tangan terangkat, punggung terlalu membungkuk, kepala terangkat dan sebagainya. Semakin postur kerja tidak alamiah maka akan semakin meningkatkan risiko timbulnya keluhan pada sistem muskuloskeletal. Postur kerja yang tidak alamiah secara umum disebabkan oleh karakteristik tuntutan tugas, alat kerja dan stasiun kerja yang tidak sesuai dengan kemampuan dan keterbatasan pekerja.

Salah satu cara untuk menilai postur kerja adalah dengan menggunakan metode Rapid Entire Body Assessment (REBA) yang digunakan untuk menganalisa pekerjaan berdasarkan posisi tubuh. Metode ini diciptakan untuk mengevaluasi aktivitas atau pekerjaan, dimana pekerjaan tersebut cenderung menyebabkan ketidaknyamanan misalnya kelelahan pada leher, tulang punggung, lengan, dan sebagainya. Hasil nilai ini menunjukkan tingkatan atau level Risiko yang dihadapi oleh karyawan dalam melakukan pekerjaannya dan terhadap beban kerja yang ditanggungnya.

Pengukuran keluhan-keluhan otot yang dialami pekerja dilakukan dengan metode Nordic Body Map menggunakan lembar penilaian berupa gambar tubuh (body map) yang merupakan cara yang sangat sederhana dan mudah dipahami dimana observer langsung mewawancarai responden mengenai otot skeletal bagian mana saja yang mengalami gangguan kenyerian atau sakit, atau menunjukkan langsung pada setiap otot skeletal sesuai yang tercantum dalam lembar kuesioner Nordic Body Map (Tarwaka, 2015).

Aleyya Batik merupakan salah satu home industry batik yang terletak di wilayah Ngawen, Tancep, Gunung Kidul. Batik yang diproduksi berupa batik tulis dan batik cap. Proses produksi pembuatan batik sendiri terdiri dari langkah persiapan, pembuatan pola, proses membatik (cap maupun tulis), proses pewarnaan dan proses pengeringan. Proses tersebut membutuhkan peran manusia untuk menciptakan produk yang berkualitas.

Kegiatan membatik terdiri dari atas beberapa gerakan repetitif yang dilakukan dalam waktu yang lama. Kegiatan tersebut meliputi aktivitas mencanting pada permukaan kain mori serta menjangkau cairan "malam" pada kompor. Para pengrajin batik tulis pada umumnya bekerja dengan cara duduk. Kursi yang digunakan merupakan kursi pendek yang disebut "dingklik". Kursi jenis ini juga tidak memiliki sandaran punggung, sehingga untuk menopang beban batang tubuh, postur pekerja akan cenderung membungkuk. Desain kursi dan gawangan yang umumnya digunakan saat ini dibuat tanpa mempertimbangkan postur pekerja dan kaidah ergonomi sehingga untuk menopang beban batang tubuh, postur pekerja dan kaidah ergonomi. Kondisi kerja tersebut menyebabkan pengrajin batik selalu berada pada sikap kerja yang tidak alamiah dan berpotensi menimbulkan ketidaknyamanan kerja.

Proses pembuatan baik tulis perlu diperhatikan kenyamanan tempat kerja dari pengrajin batik. Menurut Sanjaya et al (2013), keluhan-keluhan yang dialami oleh pengrajin batik tulis di Industri Batik Tulis Karang Kabupaten Tuban adalah keluhan pada leher, punggung, lengan atas kanan dan kiri, pinggang, lengan bawah kanan dan kiri, betis kanan dan kiri, pantat serta paha kiri dan kanan. Berdasarkan penelitian Pamungkas (2013), stasiun kerja pengrajin yang tidak ergonomis menyebabkan keluhan subyektif diantaranya keluhan pada pantat sebesar $70,00 \%$, keluhan pada bahu 90,00\%, keluhan pada pinggang $70,00 \%$, keluhan pada lengan atas sebesar $80,00 \%$, keluhan pada leher sebesar $100,00 \%$, keluhan pada lengan bawah sebesar $80,00 \%$ dan keluhan pada punggung sebesar $80,00 \%$. Penyebab yang menimbulkan permasalahan tersebut antara lain umur, jenis kelamin pekerja, ukuran antropometri tubuh dan sikap kerja pekerja

Berdasarkan uraian di atas menunjukkan bahwa stasiun kerja yang tidak ergonomis dan postur kerja dapat mempengaruhi aktivitas dan produktivitas yang akan memberikan dampak negatif bagi pekerja maupun perusahaan. Tujuan dari penelitian ini yaitu untuk mengevaluasi postur kerja pengrajin batik tulis dan mengidentifikasi keluhan subyektif yang dirasakan oleh pengrajin batik tulis di Aleyya Batik, Yogyakarta.

\section{METODE}

Penelitian ini berdasarkan waktu penelitian merupakan penelitian cross sectional karena pengumpulan data dan 
pengukuran dilakukan dalam satu waktu. Menurut analisisnya penelitian ini bersifat deskriptif yaitu menggambarkan dan mendiskripsikan suatu keadaan.

Populasi penelitian penelitian ini adalah semua pengrajin batik tulis di Aleyya Batik Yogyakarta yang berjumlah 15 orang. Teknik pengambilan sampel dalam untuk penelitian ini adalah total populasi. Penelitian ini dilaksanakan di home industry yang bernama Aleyya Batik yang terletak di Ngawen, Tancep, Gunung Kidul, Yogyakarta. Pengambilan data dilaksanakan pada tanggal 17 November 2015. Sedangkan variabel dalam penelitian ini adalah postur kerja dan keluhan subyektif.

Penelitian ini menggunakan data primer yaitu pemberian kuesioner kepada pengrajin batik tulis mengenai keluhan otot-otot skeletal dengan kuesioner Nordic Body Maps (NBM), melakukan observasi terhadap postur kerja pengrajin batik tulis di Aleyya Batik Yogyakarta dengan cara mendokumentasikan postur kerja kemudian foto tersebut dianalisis dengan menggunakan metode Rapid Entire Tabel 1. Distribusi Pengrajin Batik Tulis Berdasarkan Usia di Aleyya Batik pada Bulan November Tahun 2015

\begin{tabular}{ccc}
\hline Usia (tahun) & Frekuensi (orang) & Presentase (\%) \\
\hline$>48$ & 3 & 20,00 \\
$43-48$ & 4 & 26,67 \\
$37-42$ & 2 & 13,33 \\
$31-36$ & 6 & 40,00 \\
Total & 15 & 100,00
\end{tabular}

Sumber: Data Primer Tahun 2015
Berdasarkan tabel 1 diketahui bahwa pengrajin batik tulis di home industry Aleyya Batik berada pada kisaran usia 31 tahun sampai 58 tahun dan sebagian besar berusia 31 sampai 36 tahun.

\section{Postur kerja}

Penilaian postur kerja pengrajin batik tulis dengan mendokumentasikan dalam
Body Assessment (REBA). Teknik analisis yang digunakan dalam penelitian ini adalah menggunakan analisis deskriptif kualitatif. Data yang diperoleh disajikan dalam bentuk tabel dan analisisnya diuraikan dalam bentuk narasi.

\section{HASIL}

Distribusi Karakteristik Pengrajin Batik Tulis Di Aleyya Batik

\section{Jenis Kelamin Pengrajin Batik Tulis}

Hasil dari wawancara dan kuisioner terhadap 15 pengrajin batik tulis di Aleyya Batik Yogyakarta pada bulan November 2015, diketahui bahwa distribusi data menurut jenis kelamin menunjukkan pengrajin batik tulis di home industry Aleyya Batik semuanya memiliki jenis kelamin perempuan.

\section{Usia Pengrajin Batik Tulis}

Berikut ini adalah distribusi pengrajin batik tulis Aleyya Batik Yogyakarta berdasarkan usia: 


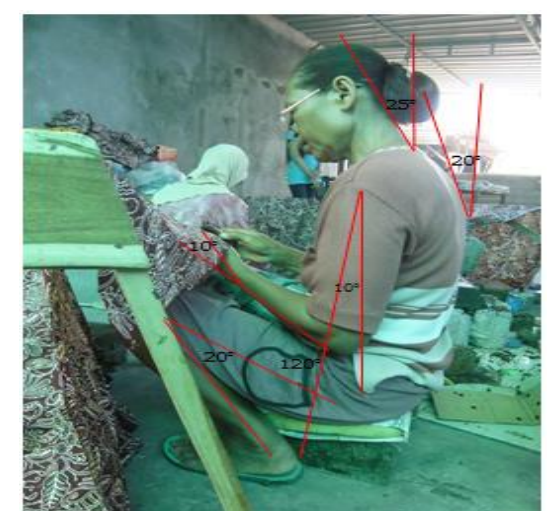

Gambar 1. Penilaian Postur Kerja Bagian Kiri Responden 1 Di Aleyya Batik Tahun 2015

Gambar 1 merupakan dokumentasi postur kerja dari salah satu pengrajin batik tulis dari posisi tubuh bagian kiri yang kemudian dilakukan penilaian sudut-sudut dari bagian anggota tubuh dengan menggunakan busur.

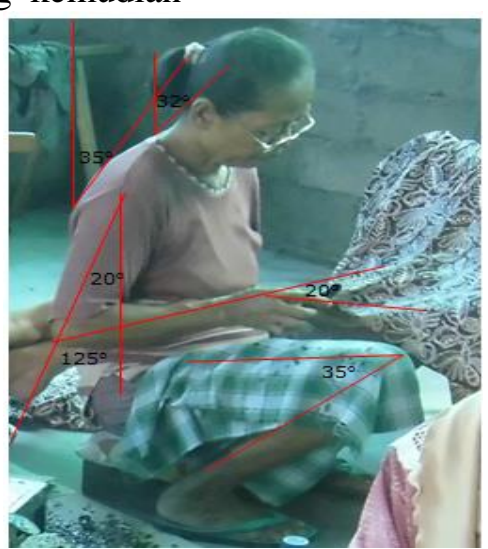

Gambar 2. Penilaian Postur Kerja Bagian Kanan Responden 1Di Aleyya Batik Tahun 2015

Gambar 2 merupakan dokumentasi postur kerja dari salah satu pengrajin batik tulis dari posisi tubuh bagian kanan yang kemudian dilakukan penilaian sudut-sudut dan diskoring dengan metode REBA.

\section{Skor Group A}

Metode REBA dimulai dengan melakukan penilaian group A terdiri dari skoring badan (trunk), skoring leher (neck) dan skoring kaki (leg).

Skoring badan pada responden 1 berdasarkan Gambar 1 hasil pengukuran sudut badan diperoleh hasil sebesar $20^{\circ}$. Hasil tersebut jika disesuaikan dengan tabel skoring REBA maka posisi badan pengrajin batik tulis ketika melakukan aktivitas membatik mendapatkan skoring sebesar dua. Skor posisi tersebut dapat ditambah 1 apabila pekerja melakukan pekerjaan dengan posisi membungkuk dan atau memuntir secara lateral. Responden 1 pada saat melakukan pekerjaan tidak berada pada posisi badan yang membungkuk dan atau memuntir secara lateral sehingga skor tidak ditambahkan 1 .

Skoring leher pada responden 1 menunjukkan posisi sudut leher sebesar $25^{\circ}$. Hasil tersebut kemudian disesuaikan dengan tabel REBA menghasilkan skor 2. Skor posisi leher dapat ditambah skor satu apabila responden melakukan pekerjaan dengan posisi leher membungkuk dan atau memuntir secara lateral. Responden 1 pada saat melakukan pekerjaan tersebut berada pada posisi leher yang memuntir dan atau membungkuk sehingga skor tesebut ditambahkan satu dan skor posisi leher menjadi tiga.

Skoring kaki menunjukkan posisi kaki pada responden 1 pada saat melakukan pekerjaan kedua kaki tertopang dengan baik di lantai dalam keadaan duduk. Skoring kaki jika disesuaikan dengan tabel skoring REBA diperoleh hasil 1. Skor posisi kaki tersebut dapat ditambah skor 1 jika pekerja melakukan pekerjaan dengan posisi salah satu atau kedua kaki ditekuk fleksi antara sudut $30^{\circ}$ sampai $60^{\circ}$. Sedangkan skor dapat ditambah skor 2 apabila 
posisi salah satu atau kedua kaki ditekuk fleksi $>60^{\circ}$. Namun karena pengrajin batik tulisketika membatik dalam keadaan duduk, maka keadaan tersebut dianggap tidak menekuk dan karenanya skoring kaki pada resonden ke 1 tetap 1.

Hasil perhitungan postur kerja group A terhadap responden 1 pengrajin batik tulis kemudian dimasukkan ke dalam tabel skor Tabel 2. Hasil Skor Awal Group A Seluruh Responden Pengrajin Batik Tulis Di Aleyya Batik pada Bulan November Tahun 2015

\begin{tabular}{ccccc}
\hline Responden & Skor Leher & Skor Badan & Skor Kaki & $\begin{array}{c}\text { Skor Awal Group } \\
\text { A }\end{array}$ \\
\hline 1 & 2 & 3 & 1 & 4 \\
2 & 3 & 3 & 1 & 5 \\
3 & 3 & 2 & 1 & 4 \\
4 & 2 & 2 & 1 & 3 \\
5 & 3 & 3 & 1 & 5 \\
6 & 2 & 2 & 2 & 4 \\
7 & 2 & 1 & 2 & 2 \\
8 & 3 & 3 & 1 & 5 \\
9 & 2 & 2 & 2 & 4 \\
10 & 2 & 1 & 2 & 5 \\
11 & 2 & 3 & 2 & 4 \\
12 & 2 & 3 & 1 & 6 \\
13 & 3 & 3 & 2 & 5 \\
14 & 3 & 3 & 1 & 4 \\
15 & 2 & 2 & 2 & \\
\hline
\end{tabular}

Berdasarkan Tabel 2 menunjukkan bahwa dari 15 responden pengrajin batik tulis di Aleyya Batik Yogyakarta untuk nilai skor awal group A berada pada kisaran antara 2 sampai dengan 6.

\section{Skor untuk Beban atau Force}

Penilaian beban diperoleh dengan membandingkan berat benda yang dibawa oleh responden selanjutnya dibandingkan dengan tabel skoring REBA. Skoring beban ditambahkan dengan skoring group A untuk mendapatkan skor A.

Pengrajin batik dalam melakukan pekerjaannya beban yang dikerjakan oleh pengrajin $<5 \mathrm{~kg}$, sehingga skor beban pada semua dalam penelitian ini adalah 0 . Berdasarkan hasil penilaian skor beban tersebut maka diketahui bahwa nilai skor A sama dengan skor awal group A dan berada pada kisaran antaraskor dua sampai dengan enam. awal group A metode REBA untuk memperoleh skor awal group A. Berdasarkan perhitungan pada postur tubuh group A diperoleh skor awal untuk group A responden 1 adalah sebesar 4 .

Berikut ini adalah rekapitulasi skor awal untuk group A pengrajin batik tulis di Aleyya Batik Yogyakarta:

\section{Skor Group B}

Langkah setelah penilaian group A adalah melakukan penilaian terhadap anggota tubuh group B yaitu tubuh bagian atas (lengan, lengan bawah, dan pergelangan tangan) pada kedua sisi kiri dan kanan.

Skoring lengan atas pada responden ke 1 berdasarkan dokumentasi pada Gambar 3 diketahui bahwa sudut antara lengan dan badan bagian kanan sebesar $20^{\circ}$. Jika disesuaikan dengan tabel REBA maka skor lengan atas bagian kanan adalah 1 . Skor lengan dapat ditambah atau dikurangi jika bahu pekerja terangkat, jika lengan diputar, diangkat menjauh dari badan atau dikurangi 1 jika lengan ditopang selama bekerja. Kondisi tersebut akan menyebabkan suatu peningkatan atau penurunan skor postur lengan. Postur lengan responden 1 ketika bekerja berada dalam posisi lengan diputar dan diangkat menjauhdari badan ketika mengambil malam yang akan digunakan untuk membatik sehingga skor lengan bagian kanan ditambah 1 menjadi 2 .

Berdasarkan dokumentasi pada Gambar 2, sudut lengan atas bagian kiri juga 
menunjukkan sudut sebesar $20^{\circ}$ maka skor untuk lengan atas bagian kiri sebesar 1. Ketika membatik lengan kanan pengrajin batik tulis digunakan untuk menopang kain mori yang akan dibatik berarti posisi lengan kanan tidak diputar dan diangkat menjauh dari badan sehingga skor lengan atas bagian kiri tetap 1 .

Skoring lengan bawah dinilai dari kisaran sudut yang dibentuk oleh lengan bawah pengrajin batik tulis selama melakukan pekerjaan. Posisi lengan bawah bagian kanan responden ke 1 pada Gambar 2 ketika bekerja membentuk sudut $120^{\circ}$, maka skor untuk lengan bawah bagian kanan adalah 2 . Sedangkan posisi lengan bawah bagian kiri responden ke 1 membentuk sudut sebesar $125^{\circ}$. Karena sudut tersebut juga $>100^{\circ}$ maka sesuai dengan tabel REBA skor lengan bawah bagian kiri adalah 2.

Skoring pergelangan tangan dinilai berdasarkan sudut yang menekuk pada pergelangan tangan. Pada responden ke 1, posisi pergelangan tangan bagian kanan (Gambar 2) menunjukkan sudut yang dibentuk sebesar $10^{\circ}$. Sesuai dengan tabel REBA posisi pergelangan tangan yang fleksi atau ekstensi antara $0-15^{\circ}$ maka memperoleh skor 1 . Skor pergelangan tangan akan ditambah 1, apabila pergelangan tangan pengrajin batik tulis pada saat bekerja menekuk ke atas atau ke bawah. Karena ketika membatik posisi pergelangan tangan kanan bisa menekuk ke atas maupun ke bawah maka skor pergelangan tangan kanan responden ke 1 adalah sebesar 2 .

Posisi pergelangan tangan bagian kiri responden ke 1 (Gambar 1) membentuk sudut sebesar $20^{\circ}$. Sudut tersebut $>15^{\circ}$ maka skor untuk pergelangan tangan bagian kiri sebesar

Tabel 3. Hasil Skor B pada Responden Pengrajin Batik Tulis Di Aleyya Batik pada Bulan November Tahun 2015

\begin{tabular}{ccc}
\hline Responden & Skor B Kanan & Skor B Kiri \\
\hline 1 & 3 & 2 \\
2 & 3 & 2 \\
3 & 2 & 2 \\
4 & 2 & 1 \\
5 & 3 & 2 \\
6 & 2 & 1 \\
7 & 3 & 2 \\
8 & 2 & 1 \\
9 & 2 & 2 \\
10 & 3 & 3 \\
11 & 4 & 2 \\
12 & 2 & 3 \\
13 & 3 & 1 \\
\hline
\end{tabular}

2. Posisi pergelangan tangan kanan responden ketika membatik tidak menekuk baik ke atas maupun ke bawah, maka skor pergelangan tangan bagian kiri tidak ditambahkan 1 .

Tahap selanjutnya adalah menghitung skor awal group B. Skor tersebut kemudian disesuaikan dengan tabel skoring REBA untuk mendapatkan skor awal pada group B. Hasil penilaian terhadap responden 1 menunjukkan bahwa skoring lengan atas bagian kanan adalah 2 , skoring lengan bawah adalah 2 dan skor pergelangan tangan kanan adalah 2. Skoring tersebut disesuaikan dengan tabel B sehingga skor awal group B pada responden ke 1 adalah 3.

\section{Skor untuk Pegangan}

Skoring pegangan didapatkan dari hasil membandingkan pegangan yang dibawa oleh responden kemudian membandingkan dengan tabel skoring REBA. Skor pegangan dijumlahkan dengan skor awal group B untuk mendapatkan skor B.

Skor B = Skor Awal Group B + Skor Pegangan

Pengrajin batik tulis di Aleyya Batik Yogyakarta ketika membatik memegang alat yang dinamakan canting. Berdasarkan hasil observasi pegangan canting yang digunakan oleh pengrajin batik tulis di Aleyya Batik, Yogyakarta dalam kondisi yang baik, sehingga skor pegangan untuk semua responden adalah 0 dan skor $B$ pengrajin tidak mengalami perubahan.

Berikut adalah hasil dari skor B untuk semua responden pengrajin batik tulis di Aleyya Batik Yogyakarta pada bulan November Tahun 2015: 


\begin{tabular}{ccc}
\hline Responden & Skor B Kanan & Skor B Kiri \\
\hline 14 & 3 & 2 \\
15 & 2 & 2 \\
\hline
\end{tabular}

Berdasarkan Tabel 3 menunjukkan bahwa perolehan skor B pengrajin batik tulis di Aleyya Batik Yogyakarta pada bagian kanan dan bagian kiri. Hasil untuk skor B kanan berada pada kisaran skor 2 sampai 4 dan skor B kiri pengrajin batik tulis berada pada kisaran skor 1 sampai 3. Hasil perolehan tersebut akan digunakan untuk penilaian skor group $\mathrm{C}$ pengrajin batik tulis di Aleyya Batik Yogyakarta.

\section{Skor Group C}

Tabel 4. Skor C Pengrajin Batik Tulis Di Aleyya Batik Di Aleyya Batik pada Bulan November Tahun 2015

\begin{tabular}{ccc}
\hline Responden & Skor C Kanan & Skor C Kiri \\
\hline 1 & 4 & 4 \\
2 & 4 & 4 \\
3 & 4 & 4 \\
4 & 3 & 2 \\
5 & 4 & 4 \\
6 & 4 & 3 \\
7 & 2 & 2 \\
8 & 4 & 4 \\
9 & 4 & 4 \\
10 & 2 & 2 \\
11 & 5 & 4 \\
12 & 4 & 4 \\
13 & 6 & 4 \\
14 & 4 & 4 \\
15 & 4 & 4 \\
\hline
\end{tabular}

Berdasarkan Tabel 4 menunjukkan hasil rekapitulasi skor $\mathrm{C}$ kanan dan kiri untuk semua pengrajin batik tulis. Skor C kanan menunjukkan bahwa dua orang memperoleh skor 2, satu orang memperoleh skor 3, sepuluh orang memperoleh skor 4, satu orang memperoleh skor 5 dan satu orang memperoleh skor 6. Skor C kiri pengrajin batik di Aleyya Batik menunjukkan hasil bahwa tiga orang memperoleh skor 2, satu orang memperoleh skor 3, dan sebelas orang memperoleh skor 4.
Skor Group C adalah hasil kombinasi dari Skor A dan Skor B. Skor A dan Skor B yang diperoleh kemudian dimasukkan dalam tabel skor C REBA untuk mendapatkan skor C. Berikut ini adalah hasil skor group $\mathrm{C}$ responden ke 1 bagian kanan diperoleh hasil bahwa skor $\mathrm{C}$ untuk responden 1 diperoleh hasil skor sebesar 4.

Berikut ini merupakan hasil dari rekapitulasi penilaian skor $\mathrm{C}$ bagian kanan dan bagian kiri pada pengrajin batik tulis di Aleyya Batik Yogyakarta:

\section{Final Skor REBA}

Final skor Rapid Entire Body Assessment (REBA) diperoleh dari hasil penambahan antara skor tabel $\mathrm{C}$ dengan peningkatan jenis aktivitas otot. Pengrajin batik tulis di Aleyya Batik Yogyakarta dalam melakukan aktivitas pekerjaannya terdapat gerakan repetitif yaitu ketika pengrajin mengambil malam dari wajan untuk melukis batik di kain. Karena adanya gerakan repetitif tersebut maka skoring untuk jenis aktivitas otot pada responden pengrajin batik adalah 1 .

Berikut ini adalah final skor dari hasil perhitungan penambahan jenis aktivitas otot pengrajin batik tulis di Aleyya Batik Yogyakarta: 
Tabel 5. Skor Aktivitas Otot dan Skor Final REBA pada Responden Pengrajin Batik Tulis Di Aleyya Batik pada Bulan November Tahun 2015

\begin{tabular}{cccccc}
\hline $\begin{array}{c}\text { Respond } \\
\text { en }\end{array}$ & $\begin{array}{c}\text { Skor } \\
\text { Aktivitas } \\
\text { Otot }\end{array}$ & $\begin{array}{c}\text { Skor Final } \\
\text { REBA } \\
\text { Kanan }\end{array}$ & & $\begin{array}{c}\text { Skor Final } \\
\text { REBA Kiri }\end{array}$ & Kategori Risiko \\
\hline 1 & 1 & 5 & & 5 & Sedang \\
2 & 1 & 5 & Sedang & 5 & Sedang \\
3 & 1 & 5 & Sedang \\
4 & 1 & 4 & Kategori Risiko & 3 & Rendah \\
5 & 1 & 5 & Sedang & 5 & Sedang \\
6 & 1 & 5 & Sedang & 4 & Sedang \\
7 & 1 & 3 & Rendah & 3 & Rendah \\
8 & 1 & 5 & Sedang & 5 & Sedang \\
9 & 1 & 5 & Sedang & 5 & Sedang \\
10 & 1 & 3 & Rendah & 3 & Rendah \\
11 & 1 & 6 & Sedang & 5 & Sedang \\
12 & 1 & 5 & Sedang & 5 & Sedang \\
13 & 1 & 7 & Sedang & 5 & Sedang \\
14 & 1 & 5 & Sedang & 5 & Sedang \\
15 & 1 & 5 & Sedang & 5 & Sedang \\
\hline
\end{tabular}

Berdasarkan Tabel 5 menunjukkan bahwa skor final REBA bagian kanan sebanyak dua pengrajin batik tulis termasuk kategori rendah dan tiga belas pengrajin batik tulis di Aleyya Batik termasuk dalam kategori risiko sedang. Sedangkan kategori skor final

Tabel 6. Distribusi Skor Final REBA Bagian Kanan dan Kiri Pengrajin Batik Tulis Di Aleyya Batik pada Bulan November Tahun 2015

\begin{tabular}{lcccc}
\multirow{2}{*}{ Kategori Risiko } & \multicolumn{2}{c}{ Skor Final REBA Bagian Kanan } & \multicolumn{2}{c}{ Skor Final REBA Bagian Kiri } \\
\cline { 2 - 5 } & $\mathbf{N}$ & $\mathbf{\%}$ & $\mathbf{N}$ & $\mathbf{\%}$ \\
\hline Rendah & 2 & 13,33 & 3 & 20,00 \\
Sedang & 13 & 86,67 & 12 & 80,00 \\
\hline Total & 15 & 100 & 15 & 100 \\
\hline
\end{tabular}

Tabel 6 merupakan distribusi hasil penilaian postur kerja pengrajin batik tulis di Aleyya Batik dengan menggunakan metode REBA. Hasil penilaian menunjukkan bahwa aktivitas pengrajin batik tulis di Aleyya Batik Yogyakarta memiliki level risiko sedang. Berdasarkan nilai level risiko tersebut maka diperlukan tindakan perbaikan.
REBA (Rapid Entire Body Assessment) bagian kiri diperoleh hasil bahwa sebanyak tiga pengrajin batik tulis termasuk dalam kategori risiko rendah dan dua belas pengrajin batik tulis termasuk dalam kategori risiko sedang. 


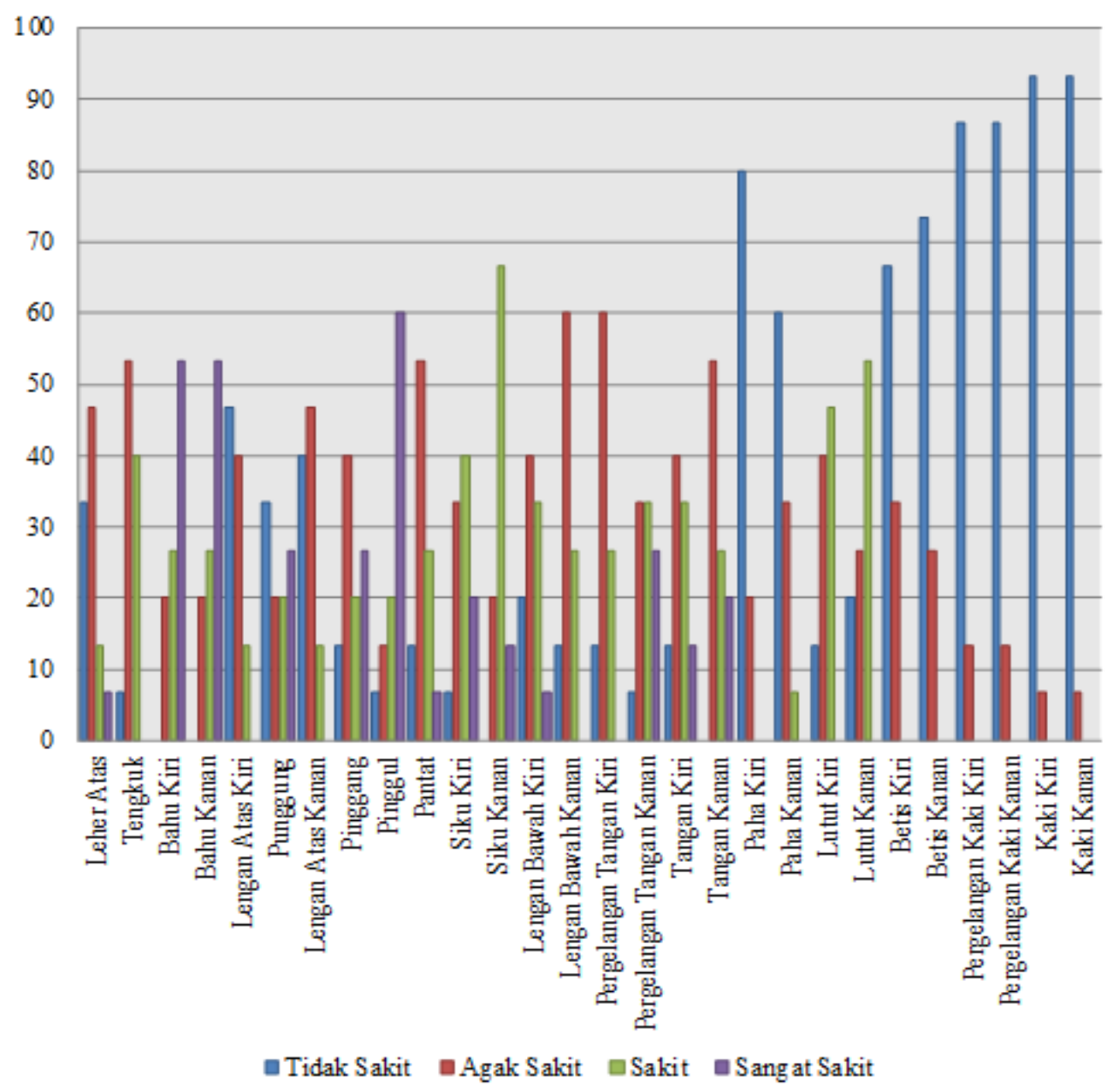

Gambar 3. Presentase Tingkat Keluhan Subyektif RespondenDi Aleyya Batik pada Bulan November Tahun 2015

Berdasarkan Gambar 3 menunjukkan bahwa responden yaitu pengrajin batik tulis Aleyya Batik mengalami keluhan pada beberapa bagian tubuh dengan tingkat keluhan agak sakit, sakit, dan sangat sakit. Keluhan agak sakit dialami pada bagian lengan bawah kanan sebesar $60,00 \%$, pergelangan tangan kiri sebesar $60 \%$, tangan kanan sebesar 53,33\%, pantat sebesar 53,33\%, dan tengkuk sebesar $53,33 \%$. Keluhan sakit dialami pada anggota tubuh seperti siku tangan sebesar $66,67 \%$ dan lutut kanan sebesar 53,33\%. Keluhan sangat sakit dialami responden pada bagian tubuh bahu kiri sebesar 53,33\%, bahu kanan sebesar $53,33 \%$, dan pinggul sebesar $60,00 \%$.

Keluhan yang telah diketahui melalui wawancara dengan kuesioner nordic body map untuk setiap individu dapat digunakan untuk mengetahui tingkat risiko otot skeletal berdasarkan total skor individu. Pengolahan data tersebut menggunakan skala likert untuk masing-masing tingkat keluhan. Berikut ini adalah hasil perhitungan jumlah skor pengukuran keluhan subyektif berupa keluhan muskuloskeletal terhadap pengrajin batik tulis di Aleyya Batik.

Berikut ini merupakan hasil pengolahan data untuk mengetahui klasifikasi subyektifitas tingkat risiko otot skeletal tiap individu: 
Tabel 7. Klasifikasi Subyektifitas Tingkat Risiko Otot Skeletal Pengrajin Batik Tulis Di Aleyya Batik pada Bulan November Tahun 2015

\begin{tabular}{ccc}
\hline Tingkat Risiko & Frekuensi (orang) & Presentase (\%) \\
\hline Rendah & 4 & 27,00 \\
Sedang & 6 & 40,00 \\
Tinggi & 5 & 33,00 \\
\hline Total & $\mathbf{1 5}$ & $\mathbf{1 0 0 , 0 0}$ \\
\hline
\end{tabular}

Berdasarkan tabel 7 menunjukkan bahwa keluhan subyektif pengrajin batik tulis di Aleyya Batik Yogyakarta termasuk dalam klasifikasi rendah, sedang dan tinggi. Dimana presentase tertinggi berada pada klasifikasi tingkat risiko sedang yaitu $40 \%$ yang berarti mungkin diperlukan adanya tindakan perbaikan dikemudian hari. Sedangkan urutan kedua sebanyak 33\% termasuk tingkat risiko tinggi yang memerlukan adanya tindakan perbaikan segera.

\section{PEMBAHASAN}

\section{Karakteristik Pengrajin Batik Tulis Di Aleyya Batik}

\section{Jenis kelamin}

Berdasarkan hasil penelitian menunjukkan bahwa dari 15 pengrajin batik tulis di Aleyya Batik, Gunung Kidul semua memiliki jenis kelamin perempuan. Hal tersebut sesuai dengan penelitian Pamungkas (2013) yang menunjukkan bahwa persentase pengrajin baik tulis perempuan sebesar $66,67 \%$ dan pengrajin batik tulis laki-laki sebesar $33,33 \%$. Sehingga dapat diketahui bahwa batik tulis cenderung banyak diminati oleh perempuan daripada laki-laki.

Tingkat risiko keluhan otot sangat dipengaruhi oleh jenis kelamin karena secara fisiologis kemampuan otot laki-laki lebih kuat dibandingkan otot perempuan. Astrand \& Rodahl (1996) menyatakan bahwa kekuatan otot perempuan hanya sekitar dua pertiga dari kekuatan otot laki-laki, sehingga daya tahan otot laki-laki pun lebih tinggi dibandingkan dengan perempuan (Tarwaka, 2015).

Pekerjaan batik tulis membutuhkan tingkat keletitian yang tinggi, sehingga pengrajin batik tulis cenderung dilakukan oleh perempuan. Menurut Tarwaka (2015), meskipun kemampuan otot perempuan lebih lemah dari laki-laki namun dalam hal tertentu perempuan lebih teliti dari laki-laki.

\section{Usia}

Penelitian menunjukkan bahwa sebagian besar pengrajin batik tulis di Aleyya Batik berusia 31 sampai 36 tahun. Penelitian Umami pada tahun 2014 menunjukkan bahwa usia pengrajin batik memiliki hubungan dengan keluhan muskuloskeletal yaitu keluhan nyeri punggung bawah (Umami et al., 2014). Menurut Tarwaka (2015), kapasitas fisik seseorang berbanding lurus dengan umur dan mencapai puncaknya pada umur 25 tahun. Umur 50 sampai 60 tahun kekuatan otot akan menurun sebesar $25 \%$, kemampuan sensorismotoris menurun sebanyak $60 \%$. Selanjutnya kemampuan kerja fisik seseorang yang berumur $>60$ tahun tinggal mencapai 50\% dari umur orang yang berumur 25 tahun.

Chaffin (1979) dan Guo et al (1995) dalam Tarwaka (2015) menyebutkan bahwa secara umum keluhan muskuloskeletal mulai timbul pada usia kerja yaitu 25-65 tahun. Keluhan pertama biasanya dirasakan pada umur 35 tahun dan tingkat keluhannya akan terus meningkat seiring dengan bertambahnya umur. Hal tersebut dikarenakan kekuatan dan ketahanan otot mulai menurun pada usia setengah baya sehingga risiko terjadinya keluhan otot meningkat. Berdasarkan uraian tersebut maka pengrajin batik tulis di Aleyya Batik memiliki risiko untuk mengalami keluhan otot Musculoskeletas Disorders (MSDs).

\section{Evaluasi Postur Kerja Pengrajin Batik Tulis}

Penilaian postur kerja terhadap pengrajin batik tulis di Aleyya Batik Gunung Kidul dalam penelitian dilakukan dengan menggunakan metode REBA. Metode ini digunakan untuk menganalisa pekerjaan berdasarkan posisi tubuh, termasuk statis dan dinamis. Metode ini diciptakan untuk mengevaluasi aktivitas atau pekerjaan yang mempunyai kecenderungan untuk menimbulkan ketidaknyamanan seperti kelelahan pada lengan, leher, tulang punggung, dan lain-lain (Tarwaka, 2015). 
Tabel 6 menjelaskan mengenai skor final REBA bagian kanan dan kiri responden pengrajin batik tulis di Aleyya Batik sebagian besar tergolong dalam kategori sedang. Hal tersebut terjadi karena ketika pengrajin batik tulis melakukan proses membatik dengan aktivitas yang monoton disertai gerakan repetitif selama 8 jam sehari. Postur kerja yang tidak alamiah serta berlangsung dalam waktu yang lama dapat menyebabkan pengrajin batik tulis akan mengalami beberapa keluhankeluhan otot (muskuloskeletal) dan keluhankeluhan lainnya sehingga dapat mengakibatkan jalannya proses produksi tidak optimal (Andrian, 2013).

Posisi leher dan badan ketika membatik dalam keadaan membungkuk dimana punggung dan dada lebih condong ke depan membentuk sudut $\geq 20^{\circ}$ terhadap garis vertikal, pengrajin batik tersebut juga memuntirkan leher ketika mengambil malam dari wajan. Keadaan tersebut merupakan salah satu bentuk dari postur tidak nyaman yang mempunyai risiko terjadinya gangguan pada sistem muskuloskeletal (Humantech, 1995).

Posisi kaki pengrajin batik tulis ketika membatik ada yang ditekuk menapak langsung ke lantai dan ada yang terjulur lurus kedepan karena ukuran kursi yang terlalu pendek. Sedangkan posisi tangan kanan dan kiri ketika melakukan proses membatik berbeda karena tangan kanan digunakan untuk memegang chanting untuk menggambar pola di kain mori dan tangan kiri menopang kain mori yang akan dibatik. Posisi lengan atas baik kanan maupun kiri sebagian pengrajin batik tulis membentuk sudut $>45^{\circ}$, hal tersebut termasuk juga dalam bentuk postur tidak nyaman. Menurut Humantech (1995), ketika melakukan pekerjaan dengan lengan atas membentuk sudut $\geq 45^{\circ}$ ke samping atau depan tubuh selama lebih dari 10 detik maka keadaan tersebut termasuk dalam bentuk postur tidak nyaman yang akan mempunyai risiko terjadinya gangguan sistem muskuloskeletal.

Berdasarkan uraian di atas dapat diketahui bahwa postur tidak nyaman merupakan salah satu faktor yang menyebabkan terjadinya gangguan muskuloskeletal. Hal tersebut sama dengan pendapat Tarwaka (2015) yang menyatakan bahwa keluhan muskuloskeletal disebabkan oleh sikap kerja yang tidak alamiah.

Hasil skor final REBA yang diperoleh dapat disimpulkan bahwa hasil skor final
REBA bagian kanan dan bagian kiri diperoleh hasil bahwa sebagian besar responden memperoleh skor sebesar 4-7, dimana skor tersebut tergolong dalam kategori sedang. Nilai level risiko tersebut maka postur kerja pengrajin batik tulis di Aleyya Batik diperlukan tindakan perbaikan (Tarwaka, 2015).

Tindakan perbaikan yang dapat diambil untuk memperbaiki postur kerja yang tidak nyaman adalah dengan melakukan perbaikan pada stasiun kerja sesuai dengan antropometri pengrajin batik tulis. Menurut Tarwaka (2015), perancangan stasiun kerja agar tidak terlalu banyak menjangkau, membungkuk maupun melakukan gerakan dengan posisi kepala yang tidak alamiah dapat menurunkan risiko dari muskuloskeletal disorders (MSDs).

Salah satu stasiun kerja yang diperbaiki adalah mengganti dingklik dengan kursi yang sesuai dengan antropometri. Karena perbedaan tampak pada posisi atau sikap duduk membatik di atas kursi lebih baik dibandingkan dengan posisi duduk di atas dingklik. Hal tersebut tampak pada ketidak sesuaian posisi tungkai dan kaki, sikap lengan/ tangan yang tidak alamiah pada saat mengambil cairan lilin dari wajan yang terlalu rendah. Pemakaian kursi yang lebih tinggi dan proses mengambil cairan lilin disesuaikan dengan ketinggian meja dapat mengurangi sikap kerja dan posisi kerja yang tidak alamiah yang berlangsung lama dan statis. Sehingga diharapkan keluhan yang dirasakan oleh pengrajin batik tulis lebih kecil dibandingkan dengan sikap duduk di atas dingklik (Siswiyanti, 2013).

\section{Keluhan Subyektif Pengrajin Batik Tulis}

Otot yang dalam jangka waktu lama menerima beban statis secara berulang-ulang akan menyebabkan keluhan berupa kerusakan pada ligamen, sendi dan tendon. Keluhan sampai kerusakan tersebut selanjutnya disebut dengan istilah keluhan musculosceletal disorders (MSDs) (Tarwaka, 2015).

Menurut Fitrihana dalam Suma'mur (2009), keluhan subyektif pada otot adalah salah satu indikator untuk mengevaluasi penerapan ergonomi. Faktor pekerjaan yang mempengaruhi kekuatan otot dan menimbulkan keluhan otot antara lain posisi kerja yang tidak alamiah, pengulangan pekerjaan pada satu jenis otot, tenaga yang berlebihan, posisi kerja yang statis, terjadi kontak bagian tubuh dengan lingkungan 
ataupun peralatan kerja, metode atau cara kerja dan jam kerja yang terlalu panjang.

Berdasarkan hasil penilaian keluhan subyektif yang berupa keluhan pada otot skeletal yang dilakukan dengan menggunakan metode Nordic Body Maps (NBM) terhadap pengrajin batik tulis di Aleyya Batik yang tercantum pada gambar 4, dapat diketahui bahwa pengrajin batik tulis mengalami keluhan pada beberapa bagian tubuh dengan tingkat keluhan agak sakit, sakit, dan sangat sakit. Keluhan agak sakit dialami pada bagian lengan bawah kanan, pergelangan tangan kiri, tangan kanan, pantat, dan tengkuk. Keluhan sakit dialami pada anggota tubuh seperti pergelangan tangan kanan, siku tangan dan lutut. Keluhan sangat sakit dialami responden pada bagian tubuh bahu dan pinggul. Keluhan tersebut disebabkan oleh stasiun kerja yang tidak sesuai dengan antropometri serta postur kerja yang tidak alamiah atau tidak nyaman. Selain itu banyaknya keluhan yang dialami oleh pengrajin batik tulis dikarenakan pekerjaan yang repetitif dan dalam jangka waktu yang lama.

Hasil penilaian tentang keluhan otot skeletal yang dirasakan oleh pengrajin batik tulis di Aleyya Batik tersebut sesuai dengan hasil penelitian Oesman et al (2012) yang melakukan penilaian keluhan muskuloskeletal terhadap pengrajin batik tulis di Sleman, dimana bagian otot yang mengalami keluhan antara lain siku kanan dan kiri, bahu kanan, lengan atas kiri, lengan bawah kiri, tangan kanan dan kiri dan kanan serta pergelangan tangan kiri. Timbulnya keluhan muskuloskelatal yang dialami oleh pengrajin batik tulis karena aktivitas berulang-ulang pada saat membatik, sehingga otot menerima tekanan akibat beban kerja secara terus menerus, dan sikap serta postur kerja yang tidak alamiah (Oesman et al., 2012).

Keluhan sistem musculoskeletal dan kelelahan yang dirasakan oleh pengrajin batik tulis terjadi disebabkan karena stasiun kerja (tempat duduk) yang tidak ergonomis dan sikap kerja duduk (Siswiyanti \& Saufik, 2011). Menurut Tarwaka (2015) faktor penyebab terjadinya keluhan muskuloskeletal antara lain jenis kelamin, umur, kebiasaan merokok, kesegaran jasmani, kekuatan fisik dan antropometri.

Klasifikasi tingkat risiko digunakan untuk menentukan tindakan perbaikan. Gambar 5 menunjukkan bahwa klasifikasi tingkat risiko keluhan subyektif pengrajin batik tulis di Aleyya Batik Ypgyakarta sebagian besar tergolong dalam tingkat risiko sedang mengalami keluhan otot muskuloskeletal. Risiko sedang berarti bahwa mungkin diperlukan adanya tindakan perbaikan dikemudian hari (Tarwaka, 2015).

Tindakan perbaikan yang dilakukan harus mempertimbangkan hasil pengukuran keluhan subyektif sebelumnya. Keluhan sangat sakit yang dialami pengrajin batik tulis di Aleyya Batik Yogyakarta yaitu bahu kiri, bahu kanan dan pinggul. Tindakan yang dapat diambil berdasarkan keluhan tersebut adalah dengan perancangan tempat duduk yang sesuai dengan antropometri pengrajin batik tulis. Selain itu upaya untuk mencegah risiko keluhan MSDs yang lebih besar pada suatu pekerjaan dapat dilakukan dengan melakukan teknik peregagan otot sebelum dan sesudah beraktivitas serta relaksasi ditengah-tengah aktivitas yang dilakukan 1x dalam 2 jam selama 5 menit, memperbanyak konsumsi air minum dan olahraga secara teratur (Merina, 2013).

\section{KESIMPULAN}

Berdasarkan hasil evaluasi terhadap postur kerja pengrajin batik tulis di Aleyya Batik Gunung Kidul Yogyakarta dengan menggunakan metode REBA diperoleh hasil bahwa postur kerja pengrajin batik tulis tergolong dalam kategori sedang. Keluhan subyektif yang dialami oleh pengrajin batik tulis di Aleyya Batik yang dinilai dengan metode Nordic Body Maps (NBM) menunjukkan bahwa sebagian besar klasifikasi tingkat risiko keluhan subyektif pengrajin batik tulis di Aleyya Batik Yogyakarta tergolong tingkat risiko sedang.

\section{SARAN}

Pemilik home industry sebaiknya melakukan perbaikan tempat duduk pengrajin disesuaikan dengan ukuran antropometri pengrajin batik tulis dan pengrajin batik tulis sebaiknya melakukan melakukan peregangan atau stretching setiap 2 jam kerja atau ketika mengalami nyeri.

\section{DAFTAR PUSTAKA}

Andrian, D. 2013. Pengukuran Tingkat Risiko Ergonomi Secara Biomekanika pada Pekerja Pengangkutan Semen (Studi 
Kasus: PT Semen Baturaja). Laporan Magang. Palembang: Universitas Binadarma.

Andrian, D. 2013. Pengukuran Tingkat Risiko Ergonomi Secara Biomekanika pada Pekerja Pengangkutan Semen (Studi Kasus: PT Semen Baturaja). Laporan Magang. Palembang: Universitas Binadarma.

Humantech. 1995. Applied Ergonomic Training Manual. 2nd ed. Australia: Barkeley Vale.

Merina, A. 2013. Analisis Risiko Ergonomi dan Keluhan Musculoskeletal Disorders (MSDs) pada Fisioterapis Di Klinik Fisioterapi Salma Putra Jakarta Timur Tahun 2012. Skripsi, Universitas Indonesia, Jakarta.

Oesman, T.I., Yusuf, M. \& Irawan, L. 2012. Analisis Sikap dan Posisi Kerja pada Perajin Batik Tulis Di Rumah Batik Nakula Sadewa, Sleman. Yogyakarta: Institut Sains \& Teknologi AKPRIND.

Pamungkas, W. A. 2013. Evaluasi Faktor Ergonomi Terhadap Stasiun Kerja Pengrajin Batik Tulis Di Industri Batik Tulis Amri Jaya Sidoarjo. Skripsi, Universitas Airlangga, Surabaya.

Sanjaya, K.T. Wahyudi, S. \& Soenoko, R. 2013. Perbaikan Fasilitas Kerja Membatik Dengan Pendekatan Ergonomi untuk Mengurangi Musculoskeletal Disorders. Journal of Engineering and Management in Industrial System.

Siswiyanti. 2013. Perancangan Meja Kursi Ergonomis Pada Pengrajin Tulis Di Kelurahan Kalinyamat Wetan Kota Tegal. Tegal: Universitas Pancasakti. Jurnal Teknik Industri, 12(2), pp. 179181. doi: https://doi.org/10.23917/jiti.v12i2.644.

Siswiyanti \& Saufik L. 2011. Beban Kerja dan Keluhan Sistem Musculoskeletal pada Pembatik Tulis di Kelurahan Kalinyamat Wetan Kota Tegal. Prosiding Seminar Nasional Sains dan Teknologi.

Suma'mur, P. K. 2009. Higiene perusahaan dan kesehatan kerja (Hiperkes). Jakarta: Sagung Seto.

Tarwaka. 2015. Ergonomi Industri, Dasardasar Pengetahuan dan Aplikasi di Tempat Kerja, Surakarta: Harapan
Press. doi: 10.1007/978-1-4684-01042_6.

Umami, D. 2014. Hubungan antara Karakteristik Responden dan Sikap Kerja Duduk dengan Keluhan Nyeri Punggung Bawah (Low Back Pain) Pada Pekerja Batik Tulis. Pustaka Kesehatan. 